\title{
A COMPARISON OF RADIOCARBON AND ARCHAEOMAGNETIC DATING FROM AN ARCHAEOLOGICAL SITE IN SPAIN
}

\author{
G Catanzariti ${ }^{1,2} \cdot \mathrm{G} \mathrm{McIntosh}^{1} \cdot \mathrm{M} \mathrm{L} \mathrm{Osete}^{1} \cdot \mathrm{T} \mathrm{Nakamura}^{3} \bullet \mathrm{A} \mathrm{Z} \mathrm{Rakowski}^{1,3,4} \bullet$ \\ I Ramírez González ${ }^{5}$ Ph Lanos ${ }^{6}$
}

\begin{abstract}
Reference archaeomagnetic secular variation (SV) curves recently have been proposed for the Iberian Peninsula and may now be used for archaeomagnetic dating. Archaeomagnetic dating is a relative dating technique that is strongly dependent on the age control of the data used to construct the reference curves. In order to test the method, an archaeological structure from central Spain has been studied. Samples have been taken for both archaeomagnetic and radiocarbon dating, and the results are compared. Close agreement is observed between both techniques, with the archaeomagnetic age of AD 603999 overlapping the calibrated age of AD 770-890. These results demonstrate the reliability of the proposed reference curves as a dating tool within the Iberian Peninsula during this archaeological period.
\end{abstract}

\section{INTRODUCTION}

Archaeomagnetic dating is a relative dating technique that exploits the ability of certain archaeological features to acquire a stable remanent (permanent) magnetization parallel with and proportional to the geomagnetic field. A concise introduction is given by Aitken (1990). The main points are set out below.

The intensity $(F)$ and direction (inclination $I$; declination $D$ ) of the geomagnetic field vary in both space and time. Rapid variations are due to external sources (diurnal variation, pulsation, magnetic storms). Longer-term variations, on an annual to century timescale, are related to internal sources and are known as secular variation (SV). The characteristics of SV can be studied directly through observation data and extended back in time using historical data back to the 17th century AD. In order to study SV further in the past, it is necessary to study the paleomagnetic properties of welldated archaeological features (archaeomagnetic studies). As well as permitting the study of past geomagnetic field behavior, this information can be used to date archaeological features.

For any particular region, SV curves can be constructed that may then be used as dating tools for archaeological features from the same region. By comparing the remanent magnetization of an archaeological feature with a reference SV curve, the age of the magnetization can be determined. If the magnetization can be related to a known archaeological event, this then gives the age of the event. This condition is commonly met in heated material, which exhibits thermoremanent magnetization (TRM) from the last heating and cooling cycle of the feature. For fired material (e.g. ceramics), the event recorded is its production, while for combustion structures (e.g. kilns, furnaces) the event is their last use, which is taken to correspond to their abandonment.

Over the last $4 \mathrm{yr}$, the number of archaeomagnetic studies in Europe has grown substantially, thanks in part to the EU-funded Archaeomagnetic Applications for the Rescue of the Cultural Heritage (AARCH) network. Consequently, the number of data has increased to the point that many new reference curves are available. One example of this is in Spain and Portugal, where for the first time SV

\footnotetext{
'Facultad de Ciencias Físicas, Universidad Complutense de Madrid, Spain.

2Corresponding author. Email: gcatanza@fis.ucm.es.

${ }^{3}$ Centre for Chronological Research, Nagoya University, Japan.

${ }^{4}$ Radiocarbon Laboratory, Silesian University of Technology, Gliwice, Poland.

${ }^{5}$ Gea Patrimonio, Guadalajara, Spain.

${ }^{6}$ Civilisations Atlantiques et Archéosciences, CNRS, UMR 6566, Campus de Beaulieu, 35042, Rennes cedex, France.
} 
curves are sufficiently developed to be used for dating. Recently, Gómez-Paccard et al. (2006) proposed reference SV curves for the Iberian Peninsula (the westernmost part of mainland Europe, which includes Spain, Portugal, Andorra, and Gibraltar; Figure 1). The curves are based on 134 directional data (declination and inclination) from sites in Spain, France, and Morocco, obtained from heated archaeological features (kilns, furnaces, and burnt horizons). The curves span the last $3000 \mathrm{yr}$ and can be used for dating archaeological features from pre-Roman up to modern times.

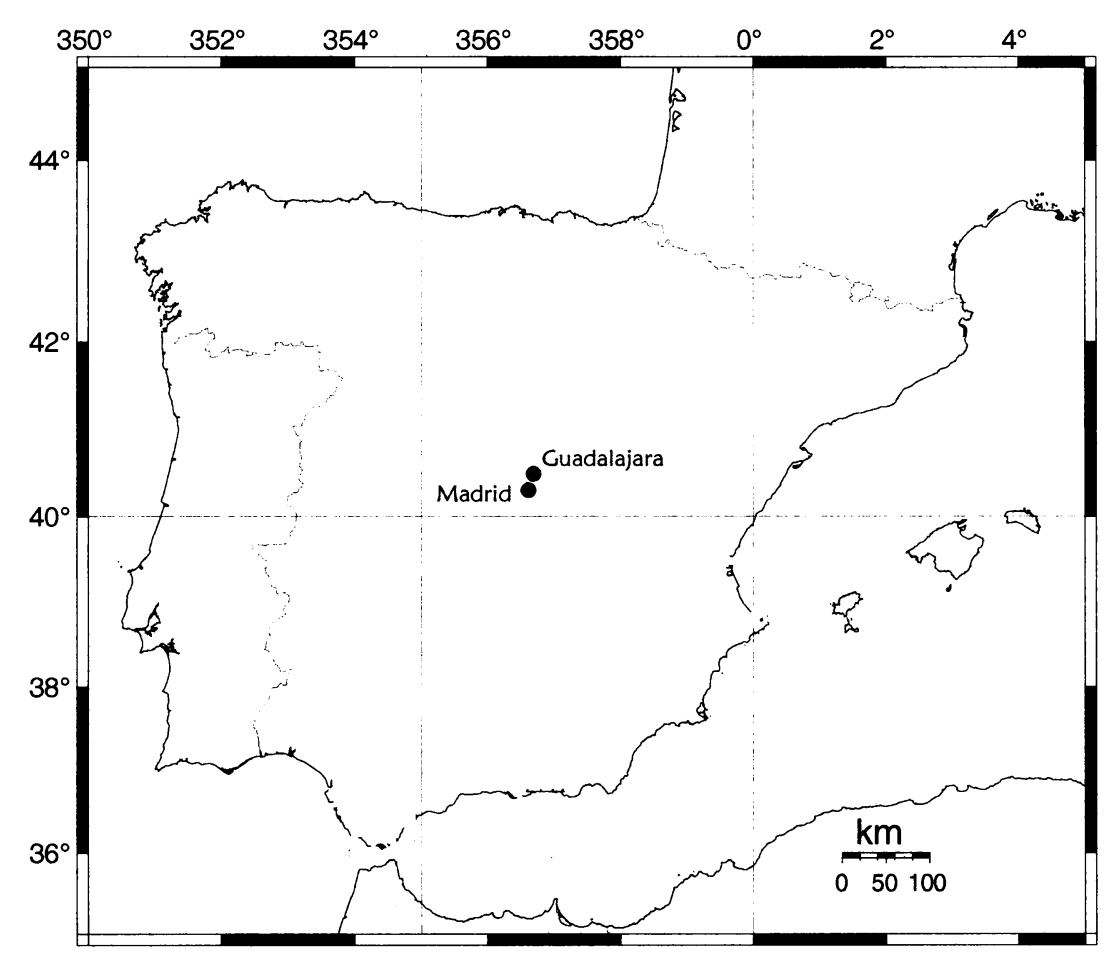

Figure 1 Map of Spain showing Guadalajara (site location) and Madrid (reference location for the SV curves).

The purpose of this study is to test the accuracy of the proposed reference curves by dating an archaeological feature using both archaeomagnetic and radiocarbon dating. For this, a kiln excavated from an archaeological site in Guadalajara, Spain, has been studied. The kiln offers wellheated, in situ remains suitable for archaeomagnetic sampling, along with abundant charcoal remains from within the combustion chamber that are suitable for ${ }^{14} \mathrm{C}$ dating. In addition, the age of the kiln is poorly constrained archaeologically, so the dating results will provide valuable information for the archaeological interpretation of the site.

\section{ARCHAEOLOGICAL CONTEXT AND MATERIALS}

Archaeological excavations carried out at the site (SUE 10; calle Ingeniero Mariño, Guadalajara; $40.6^{\circ} \mathrm{N}, 3.2^{\circ} \mathrm{E}$; Figure 1) revealed the remains of a pottery kiln in conjunction with 2 storage silos containing domestic pottery fragments. Two adobe brick pillars that originally supported the vault of the combustion chamber of the kiln were well preserved and in situ. The pillars suffered intense heating during the use of the kiln, as evidenced by the strong rubefaction and porosity of the adobe bricks. 
The kiln remains were located below horizons containing artifacts from the 14th century (the Castillian Trastamara epoch), thus defining the terminus ante quem. A reliable terminus post quem could not be established due to the broad range of ceramics recovered at the site. However, the presence of well-burnt adobe bricks and the abundance of charcoal found in the remains of the combustion chamber make the site suitable for both archaeomagnetic and ${ }^{14} \mathrm{C}$-dating techniques.

\section{SAMPLES AND METHODS}

\section{Archaeomagnetic Samples and Laboratory Methods}

Four oriented (and 2 unoriented) adobe bricks were collected from the pillars of the kiln. A thin wooden tablet was glued to the irregular upper surface of each of the 4 bricks, which was then orientated using a magnetic compass. The strike direction, dip direction, and dip angle were measured and marked. Each independently oriented brick is considered an independent sample.

The samples were first consolidated with ethyl silicate (Silbond 40), and then standard cylindrical specimens $\left(10.8 \mathrm{~cm}^{3}\right)$ were drilled from each sample, transferring the orientation mark to the specimens. A total of 16 specimens from the 4 bricks were prepared. Low field magnetic susceptibility $(K)$ was measured for each specimen using an AGICO KLY3 susceptibility meter. The natural remanent magnetization (NRM) of each specimen was measured using an AGICO JR5 spinner magnetometer. Stepwise thermal (TH) demagnetization of NRM was carried out in $50^{\circ} \mathrm{C}$ increments up to $700{ }^{\circ} \mathrm{C}$ using a Schonsted Instruments model TSD-1 thermal demagnetizer. Stepwise alternating field (AF) demagnetization was carried out in 2-5-mT steps up to $20 \mathrm{mT}$ and in 15-20-mT steps up to $100 \mathrm{mT}$ using a Schonsted Instruments model GSD-5 tumbling demagnetizer.

\section{${ }^{14} \mathrm{C}$ Samples and Laboratory Methods}

Two samples of charcoal (Guadalajara-1 and Guadalajara-2) were taken from the combustion chamber of the kiln. Samples were washed in distilled water and prepared with the widely used acidalkali-acid (AAA) method. Each sample was heated at $80^{\circ} \mathrm{C}$ in $0.5 \mathrm{M} \mathrm{HCl}$ for $12 \mathrm{hr}$ and then filtered, rinsed, and heated in $0.1 \mathrm{M} \mathrm{NaOH}\left(80^{\circ} \mathrm{C}, 12 \mathrm{hr}\right)$. Samples were then filtered, rinsed, and heated again in $0.5 \mathrm{M} \mathrm{HCl}\left(80^{\circ} \mathrm{C}, 12 \mathrm{hr}\right)$ and then refiltered, rinsed in distilled water, and dried.

Pretreated residues of samples were combined with cupric oxide and sealed into glass tubes evacuated with a rotary pump. The tubes were then placed in an electric furnace for $2 \mathrm{hr}$ at $850{ }^{\circ} \mathrm{C}$. Carbon dioxide produced from the samples was purified in a glass cryogenic vacuum-line system. Water produced during combustion was removed via a trap containing a mixture of methanol and liquid nitrogen at $183 \mathrm{~K}$. SO $\mathrm{x}_{\mathrm{x}}$ compounds were removed with an $n$-pentane trap cooled to $77 \mathrm{~K}$ by liquid nitrogen. Purified $\mathrm{CO}_{2}$ was then condensed in glass tubes using liquid nitrogen.

The prepared $\mathrm{CO}_{2}$ samples were reduced to graphite using iron powder as a catalyst (Kitagawa et al. 1993). The iron powder was prepared in a vacuum line containing hydrogen and heated for $\sim 1 \mathrm{hr}$ at $450{ }^{\circ} \mathrm{C}$. The line was evacuated, and $\mathrm{CO}_{2}$ was condensed with the iron powder using liquid nitrogen. Hydrogen was then added, and the glass tube was sealed. Reduction was done in an electric furnace at $650^{\circ} \mathrm{C}$ for $6 \mathrm{hr}$.

The resulting mixture of graphite and iron powder was dried and pressed into a target holder for accelerator mass spectrometry (AMS) ${ }^{14} \mathrm{C}$ measurements with a HVEE tandetron AMS system at Nagoya University. Each target was measured for $30 \mathrm{~min}$ in each analysis. The ${ }^{12} \mathrm{C}^{3+}$ and ${ }^{13} \mathrm{C}^{3+}$ currents were kept at 190 and $200 \mathrm{nA}$, respectively. The stable carbon isotope ratio was measured using a Finnigan MAT 252 isotope-ratio mass spectrometer at the Center for Chronological Research, 
Nagoya University (Nakamura et al. 2000). Calculation of the ${ }^{14} \mathrm{C}$ ages was done according to Stuiver and Polach (1977). Formulas presented in Mook and Plicht (1999) were used for age correction and correction for isotopic composition.

\section{RESULTS}

Natural remanent magnetization (NRM) intensities range from 0.3 to $9.8 \mathrm{Am}^{-1}$, and $K$ varies between $7.80 \times 10^{-4}$ and $1.05 \times 10^{-2}$ SI (Figure 2). Initial NRM directions are well grouped (Figure 3), and Königsberger ratios $(\mathrm{Qn}=\mathrm{NRM} / K H$, where $H=$ geomagnetic field intensity $=39.8$ $\mathrm{Am}^{-1}$ ) fall near 10, both of which are consistent with an NRM that is a thermoremanent magnetization (TRM). Stepwise demagnetization of NRM indicates that it consists of a single, stable remanence component (Figure 4). Demagnetization plots are typically represented using orthogonal projection of the remanence vector end points so that the declination is plotted on the horizontal plane (W-N axes in Figure 4) and the inclination is projected on to the vertical plane (up- $\mathrm{N}$ axes in Figure 4). In all specimens, for both TH and AF demagnetization, the linear decay of the remanence vector towards the origin of the demagnetization plot indicates a single component. In order to calculate a characteristic remanence (ChRM) direction, a least-squares fit to the linear segment of the remanence vector trending to the origin of the demagnetization plot has been calculated (Kirschvink 1980). All specimens exhibit well-defined ChRM directions that are well grouped and in close agreement with the NRM directions.

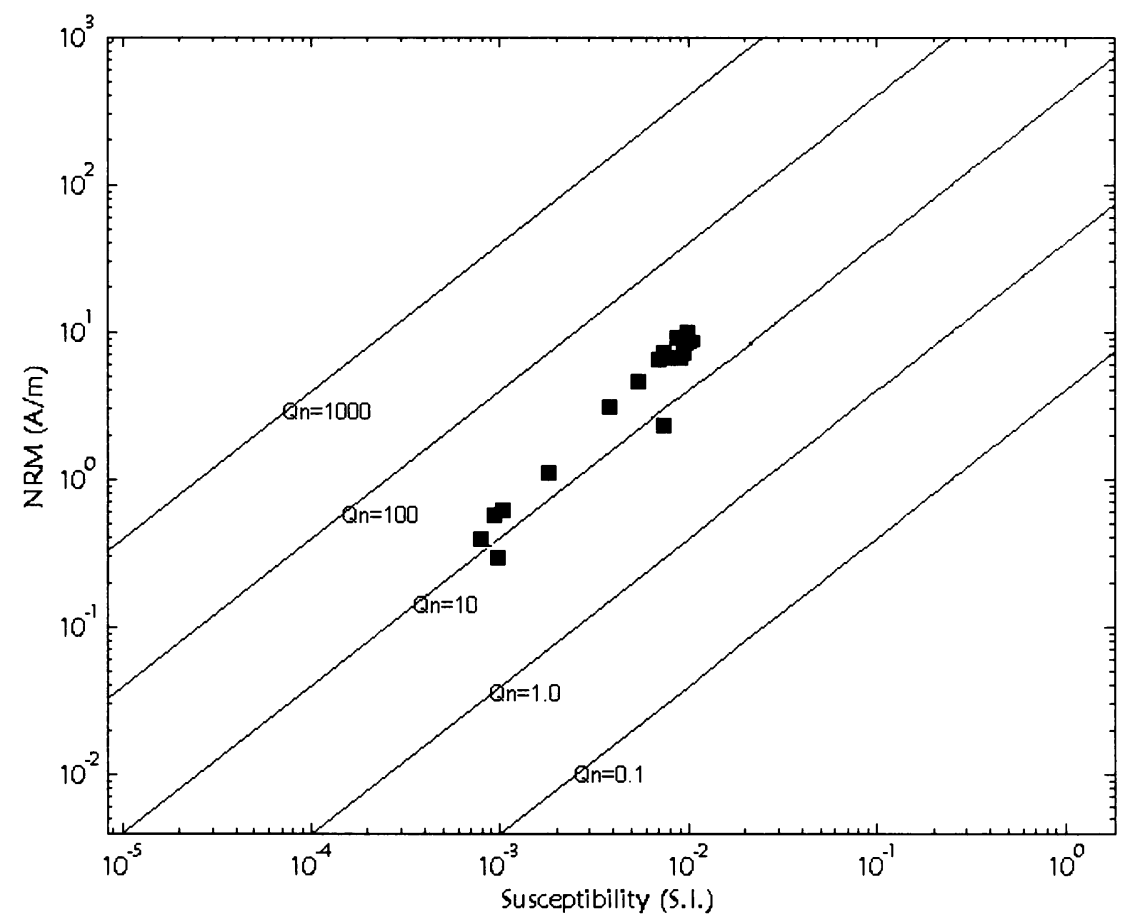

Figure 2 NRM intensity versus magnetic susceptibility $(K)$. The straight lines indicate constant values of the Königsberger ratio (Qn).

The site-mean (archaeomagnetic) direction has been determined following a hierarchical structure (specimen $\rightarrow$ sample, sample $\rightarrow$ site), so that the 16 specimen ChRMs produce a mean direction determined from 4 (independently oriented) samples. The results are summarized in Figure 5. Fisher 


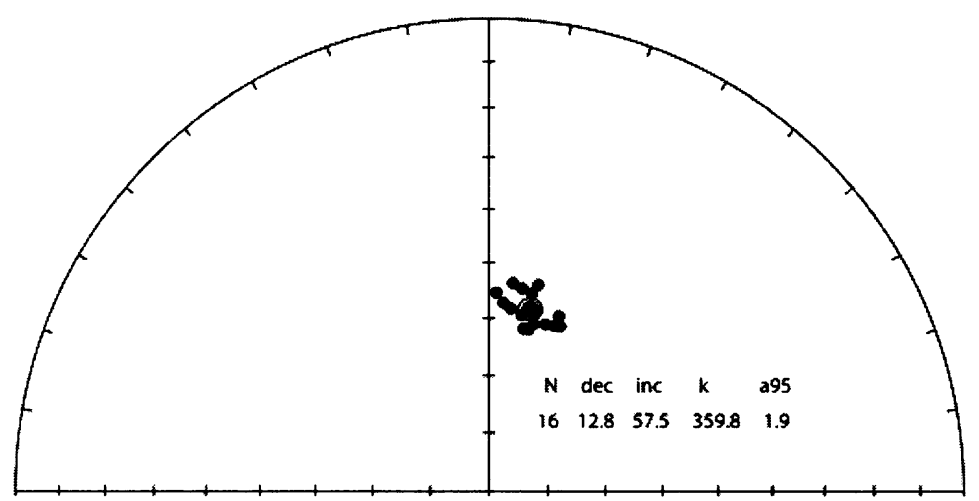

Figure 3 Equal area projection of the distribution of NRM directions. The Fisher (1953) mean values are given, with $\mathrm{N}=$ number of samples, dec $=$ declination $\left({ }^{\circ} \mathrm{E}\right)$, inc $=$ inclination $\left({ }^{\circ}\right), \mathrm{k}=$ shape/concentration parameter, a95 $=$ alpha-95 angle $\left(^{\circ}\right)$.

Thermal demagnetisation

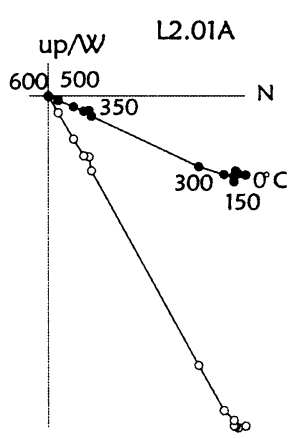

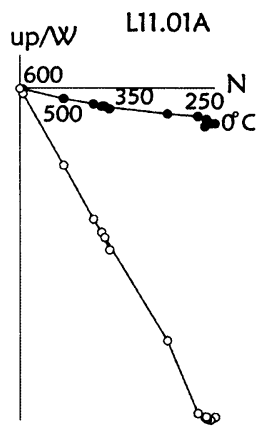

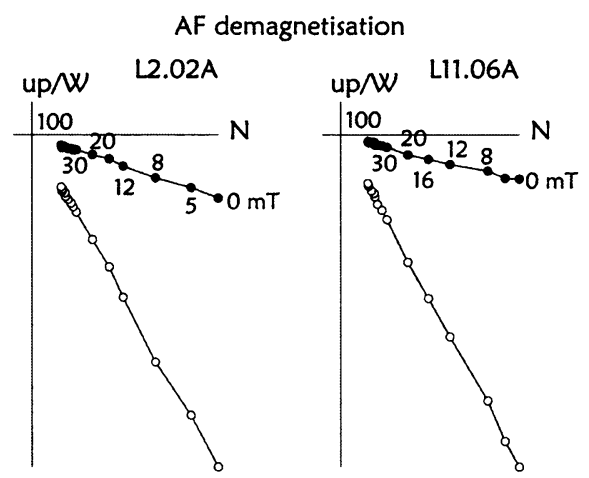

Figure 4 Orthogonal projection of the remanence vector end points. Declination is plotted on the horizontal plane (W-N axes), and the inclination is projected on to the vertical plane (up-N axes). Specimens L2.01A and L11.01A were demagnetized thermally; specimens L2.02A and L11.06A were demagnetized by alternating fields (AF).

(1953) statistics have been used to estimate the precision and reliability of the data (given by alpha$95\left[\alpha_{95}\right]$ and the concentration or shape parameter $\left.[k]\right)$. Values of $\alpha_{95}=2.8^{\circ}$ and $k=1103$ represent a well-defined archaeomagnetic direction.

Similar ${ }^{14} \mathrm{C}$ ages were obtained from the 2 charcoal samples: $1198 \pm 26$ BP for Guadalajara- 1 (NUTA-2-10558) and $1207 \pm 23$ BP for Guadalajara-2 (NUTA-2-10672). They have been combined to provide a combined mean ${ }^{14} \mathrm{C}$ age of $1203 \pm 17 \mathrm{BP}$. This represents a good analytical result, showing good consistency between the ${ }^{14} \mathrm{C}$ ages.

\section{Dating}

In order to date the SUE 10 kiln using the Gómez-Paccard et al. (2006) reference SV curves, the archaeomagnetic direction must first be relocated to Madrid, the reference location for the SV curves. This has been done via the virtual geomagnetic pole (Shuey et al. 1970; Nöel and Batt 1997). The relocated direction, listed in Figure 5, hardly changes because of the proximity of Guadalajara to Madrid. 


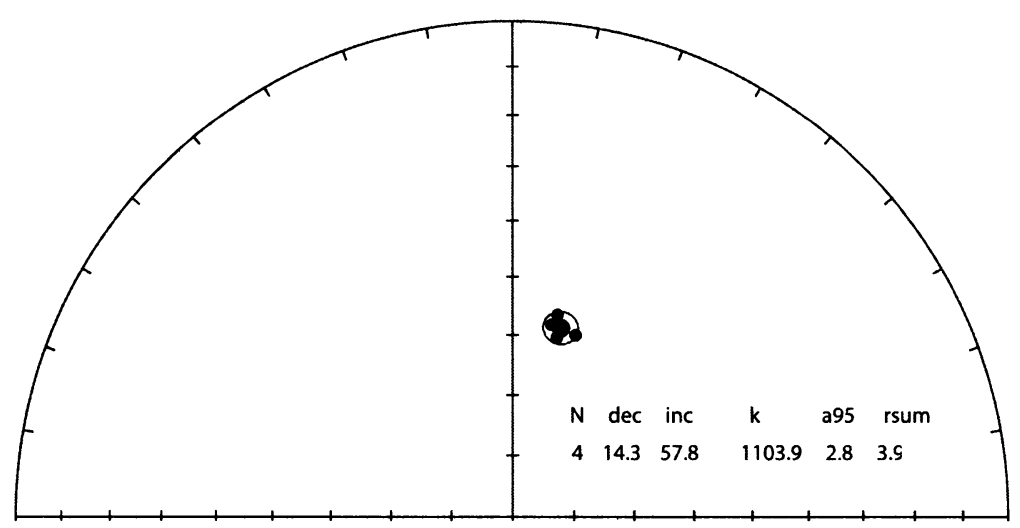

Figure 5 Equal area projection of the ChRM directions, following the hierarchical structure described in the text. The Fisher (1953) mean values are given, with $\mathrm{N}=$ number of samples, $\operatorname{dec}=\operatorname{declination}\left({ }^{\circ} \mathrm{E}\right)$, inc $=$ inclination $\left({ }^{\circ}\right), \mathrm{k}=$ shape/concentration parameter, $\mathrm{a} 95=\alpha 95=$ alpha-95 angle $\left({ }^{\circ}\right)$.

A Bayesian statistical approach was adopted both for constructing the reference SV curves and calculating the archaeomagnetic date (Lanos 2004; Gómez-Paccard et al. 2006) using the RENCURVE and RENDATE software. Probability density functions (PDF) are generated for both the declination and inclination values, which are then combined to give the overall PDF (Figure 6). The overall PDF exhibits 2 peaks, between AD 603-999 and 1547-1569, which are significant at the 95\% probability level. Since the latter is younger than the terminus ante quem defined by stratigraphical constraints, it can be discounted, resulting in an archaeomagnetic date of AD 603-999.
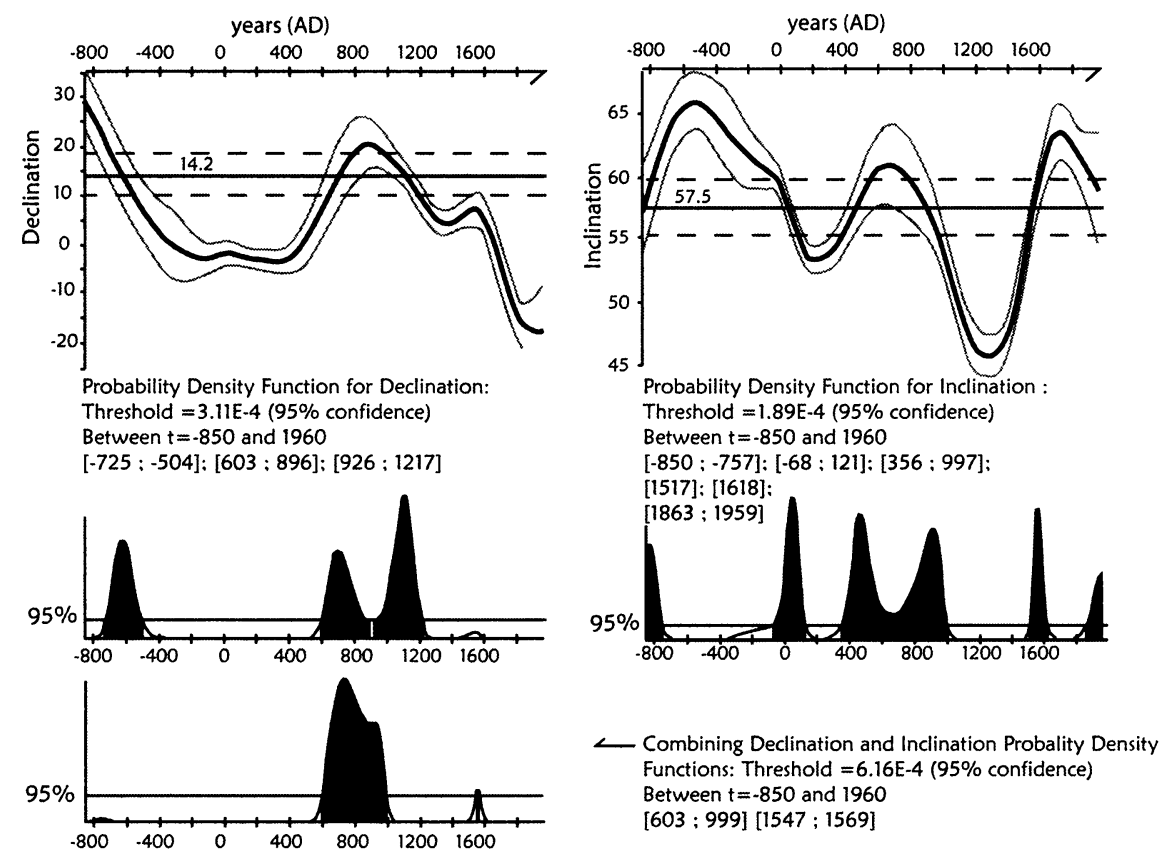

Figure 6 Archaeomagnetic dating of kiln SUE-10 for declination, inclination, and combined declination and inclination. The reference SV curves of Gómez-Paccard et al. (2006) are shown as black curves on the upper left (declination) and upper right (inclination) plots with associated error bars in gray. The archaeomagnetic direction is shown as a straight line with associated error bars as dashed lines. 
The $2{ }^{14} \mathrm{C}$ ages provide a combined mean age that has been used to calculate the calendar age using the calibration software OxCal v 3.10 (Bronk Ramsey 1995, 2001) and the IntCal04 calibration curve (Reimer et al. 2004). This gives a calendar age of between AD 770 and 890 at the $95 \%$ probability level (Figure 7), which is in close agreement with the AD 603-999 archaeomagnetic date.

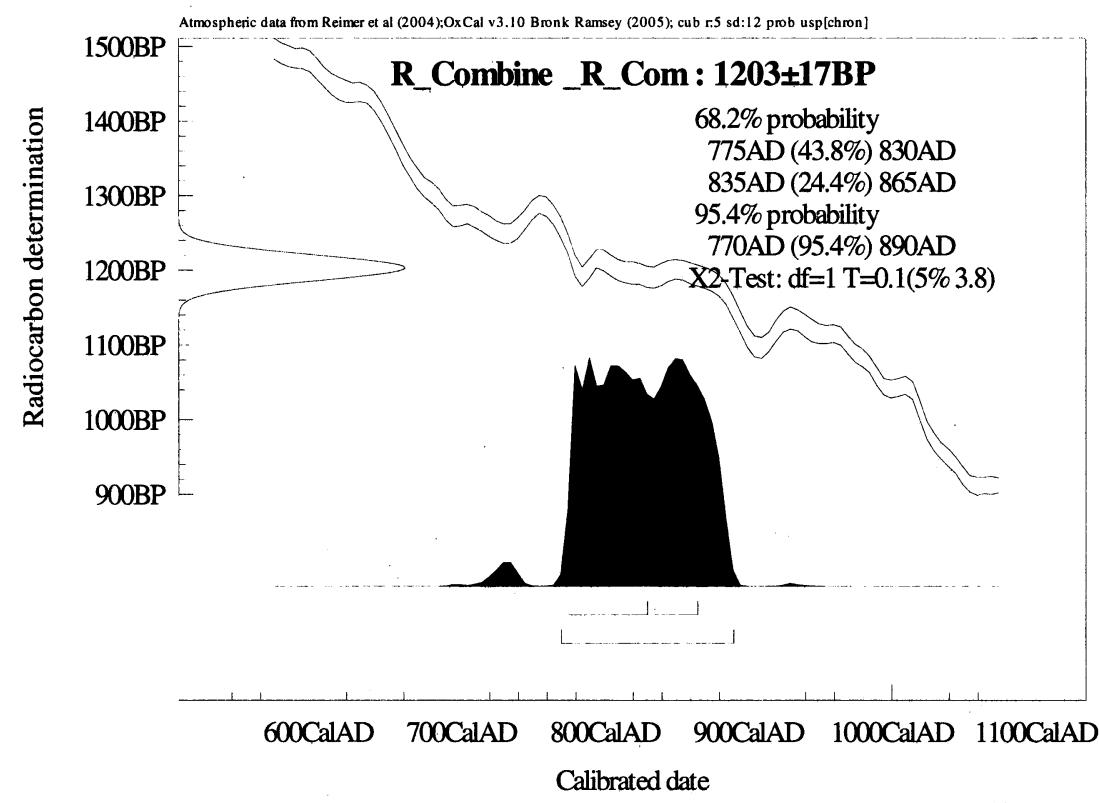

Figure 7 Result of the calibration of the weighted mean value of Guadalajara- 1 and $-2{ }^{14} \mathrm{C}$ ages

The ${ }^{14} \mathrm{C}$ method gives a more precise result than the archaeomagnetic method, with an uncertainty of $220 \mathrm{yr}$ as compared to $396 \mathrm{yr}$ (see Table 1). For the ${ }^{14} \mathrm{C}$ dating, the uncertainty of the calibrated age is larger than for the ${ }^{14} \mathrm{C}$ age because of the shape of the calibration curve, which is relatively flat at around $1200 \mathrm{BP}$ (Figure 7). For the archaeomagnetic dating, the large uncertainty is mainly due to the relatively poorly constrained reference curves between AD 500-1000. This is caused by a lack of archaeomagnetic (and archaeological) data available for reference curve construction-a problem that is common across the whole of Europe (the "Dark Ages"). A better determination of the SV in this period of time would provide a more constrained dating tool for future archaeological sites. Nevertheless, the good consistency between both dating methods has been demonstrated.

Table 1 Summary of archaeomagnetic and ${ }^{14} \mathrm{C}$ dating results: $\operatorname{dec}=\operatorname{declination}\left({ }^{\circ} \mathrm{E}\right)$; inc $=$ inclination $\left({ }^{\circ}\right)$; and $\alpha_{95}=$ confidence limit $\left({ }^{\circ}\right)$.

\begin{tabular}{lll}
\hline $\begin{array}{l}\text { Archaeomagnetic direction } \\
\left(\mathrm{dec}, \text { inc, } \alpha_{95}\right)\end{array}$ & $\begin{array}{l}\text { Relocated direction } \\
\left(\mathrm{dec}, \text { inc, } \alpha_{95}\right)\end{array}$ & $\begin{array}{l}\text { Archaeomagnetic age (AD) } \\
95 \% \text { confidence intervals }\end{array}$ \\
\hline $14.3,57.8,2.8$ & $14.2,57.5,2.8$ & $603-999,1547-1569$ \\
\hline & & $\begin{array}{l}\text { Calibrated age (AD) } \\
95 \% \text { conf. intervals }\end{array}$ \\
Sample & ${ }^{14} \mathrm{C}$ age (BP) & $720-750$ \\
\hline $\begin{array}{l}\text { Guadalajara-1 } \\
\text { (NUTA-2-10558) }\end{array}$ & $1198 \pm 26$ & $760-900$ \\
Guadalajara-2 & $1207 \pm 23$ & $720-740$ \\
(NUTA-2-10672) & & $770-890$ \\
Combined mean & $1203 \pm 17$ & $770-890$ \\
\hline
\end{tabular}




\section{CONCLUSION}

A kiln from Guadalajara, central Spain, has been dated using archaeomagnetic and ${ }^{14} \mathrm{C}$ dating. The brick samples carry a stable characteristic remanent magnetization that for allowed the determination of a well-defined archaeomagnetic direction. This direction was dated using the reference curves of Gómez-Paccard et al. (2006), giving an age of AD 603-999. Charcoal samples were taken from the remains of the combustion chamber, giving a calibrated age of AD 770-890, which is in close agreement with the archaeomagnetic age. These results demonstrate the validity of the proposed reference SV curves as a dating tool within the Iberian Peninsula during this archaeological period.

\section{ACKNOWLEDGMENTS}

This work was supported partly by the EU (Contract HPRN-CT-2002-00219, Archaeomagnetic Applications for the Rescue of the Cultural Heritage, AARCH) and by the Ministry of Education, Sciences, Sport and Culture of Japan. G Catanzariti and A Rakowski acknowledge the fellowship provided by the EU (Contract HPRN-CT-2002-00219, Archaeomagnetic Applications for the Rescue of the Cultural Heritage, AARCH). Sincere thanks are given to all staff of the Center for Chronological Research of Nagoya University for their kind support. Thanks also to Rob Sternberg and Joni Manson, whose reviews helped improve the manuscript.

\section{REFERENCES}

Aitken MJ. 1990. Science-Based Dating in Archaeology. New York: Longman. 274 p.

Bronk Ramsey C. 1995. Radiocarbon calibration and analysis of stratigraphy: the OxCal program. Radiocarbon 37(2):425-30.

Bronk Ramsey C. 2001. Development of the radiocarbon calibration program. Radiocarbon 43(2A):355-63.

Fisher R. 1953. Dispersion on a sphere. Proceedings of the Royal Society of London A 217:295-305.

Gómez-Paccard M, Chauvin A, Lanos P, McIntosh G, Osete ML, Catanzariti G, Ruiz-Martínez VC, Núñez JI. 2006. First archaeomagnetic secular variation curve for the Iberian Peninsula: comparison with other data from western Europe and with global geomagnetic field models. Geochemistry, Geophysics, Geosystems 7: Q12001; doi:10.1029/2006GC001476.

Kirschvink J. 1980. The least-squares line and plane and the analysis of paleomagnetic data. Geophysical Journal of the Royal Astronomical Society 62:699-718.

Kitagawa H, Masuzawa T, Nakamura T, Matsumoto E. 1993. A batch preparation method for graphite targets with low level background for AMS ${ }^{14} \mathrm{C}$ measurements. Radiocarbon 35(2):295-300.

Lanos Ph. 2004. Bayesian inference of calibration curves: applications to archaeomagnetism. In: Buck C, Millard, A, editors. Tools for Constructing Chronologies: Crossing Interdisciplinary Boundaries. Volume 177. London: Springer-Verlag. [RENDATE soft- ware available at URL: http://www.meteo.be/CPG/ aarch.net/index.html].

Mook WM, van der Plicht J. 1999. Reporting ${ }^{14} \mathrm{C}$ activities and concentrations. Radiocarbon 41(3):227-40.

Nakamura T, Niu E, Oda H, Ikeda A, Minami M, Takahashi H, Adachi M, Pals L, Gottdang A, Suya N. 2000. The HVEE Tandetron AMS system at Nagoya University. Nuclear Instruments and Methods in Physics Research B 172(1-4):52-7.

Nöel M, Batt C. 1997. A method for correcting geographically separated remanence directions for the purpose of archaeomagnetic dating. Geophysical Journal International 102:753-6.

Reimer PJ, Baillie MGL, Bard E, Bayliss A, Beck JW, Bertrand CJH, Blackwell PG, Buck CE, Burr GS, Cutler KB, Damon PE, Edwards RL, Fairbanks RG, Friedrich M, Guilderson TP, Hogg AG, Hughen KA, Kromer B, McCormac G, Manning S, Bronk Ramsey C, Reimer RW, Remmele S, Southon JR, Stuiver M, Talamo S, Taylor FW, van der Plicht J, Weyhenmeyer CE. 2004. IntCal04 terrestrial radiocarbon age calibration, 0-26 cal kyr BP. Radiocarbon 46(3): 1029-58.

Shuey R, Cole E, Mikulich M. 1970. Geographic correction of archaeomagnetic data. Journal of Geomagnetism and Geoelectricity 22:485-9.

Stuiver M, Polach HA. 1977. Discussion: reporting of ${ }^{14} \mathrm{C}$ data. Radiocarbon 19(3):355-63. 